\title{
ANALISIS KUALITAS LAYANAN TERHADAP KEPUASAN KONSUMEN PADA BRAJA MUSTIKA HOTEL \& CONVENTION CENTRE, BOGOR
}

\author{
Stephanie Alexandra Suwanda dan Edward Siregar \\ Departemen Manajemen, Fakultas Ekonomi dan Manajemen, \\ Institut Pertanian Bogor, Kampus Dramaga Bogor 16680 \\ e-mail: stephanie.suwanda@gmail.com dan e-mail:edward.h.siregar@gmail.com
}

\begin{abstract}
As the development on the tourism industry in Indonesia, there are number of hotels required as accomodation facilities, hence it brings rivalry among them. In a very tight competition, every hotel businessmen needs to think about making some creative ideas and increasing the service quality they would offered to the consumers. The purposes of this study are to identify consumers demographic on hotel brajamustika, to analyze the significance rates through Braja Mustika Hotel service quality, and to analyze customers satisfaction rate through Braja Mustika Hotel service quality. Analysis ofthe data used in this research is descriptive analysis, Importance Performance Analysis (IPA), and Customer Satisfaction Index (CSI). This study showed that customers satisfaction rates was occurred on the satisfied rate.
\end{abstract}

Keywords: Customer Satisfaction, Dimension of Service Quality, Hotel

\begin{abstract}
Abstrak: Sebagai pengembangan industri pariwisata di Indonesia, ada sejumlah hotel diperlukan sebagai fasilitas akomodasi, karena itu membawa persaingan di antara mereka. Dalam persaingan yang sangat ketat, hotel setiap pengusaha perlu berpikir tentang membuat beberapa ide kreatif dan meningkatkan kualitas layanan mereka akan ditawarkan kepada konsumen. Tujuan dari penelitian ini adalah untuk mengidentifikasi konsumen demografi di Hotel brajamustika, untuk menganalisis tingkat signifikansi melalui Braja Mustika Hotel kualitas layanan, dan untuk menganalisis tingkat kepuasan pelanggan melalui Braja Mustika Hotel kualitas layanan. Analisis ofthe data yang digunakan dalam penelitian ini adalah analisis deskriptif, Importance Performance Analysis (IPA), dan Customer Satisfaction Index (CSI). Studi ini menunjukkan bahwa tingkat kepuasan pelanggan yang terjadi pada tingkat puas.
\end{abstract}

Kata kunci: Kepuasan Pelanggan, Dimensi Service Quality, Hotel

\section{PENDAHULUAN}

Kota Bogor merupakan salah satu kota di Indonesia yang memiliki banyak tempat wisata. Selain tempat wisata, Kota Bogor pun menawarkan sejuta wisata kuliner yang dapat dikunjungi para penikmat kuliner khas Kota Bogor seperti tauge goreng, bolu lapis talas, macaroni panggang, pizza kayu bakar, dll. Selain itu, terdapat pula berbagai macam destinasi wisata di Kota Bogor seperti Jungle Land, The Jungle, Kebun Raya Bogor, Museum -Museum yang menarik perhatian para wisatawan dari dalam maupun luar negeri. Faktor udara yang lebih sejuk dibandingkan beberapa kota lain di sekitarnya, menjadikan Kota Bogor ramai dikunjungi wisatawan domestik maupun luar negeri pada 
akhir pekan dan liburan panjang. Berikut jumlah data pengunjung tempat wisata milik pemerintah Kota Bogor disajikan pada Tabel 1.

Tabel 1. Jumlah Konsumen tempat Wisata Milik Pemerintah Kota Bogor

\begin{tabular}{llr}
\hline No & Nama Tempat Wisata & Jumlah Pengunjung (orang) \\
\hline 1 & Kebun Raya Bogor & 1.337 .208 \\
2 & Istana Bogor & 58.731 \\
3 & Museum Zoologi & 51.748 \\
4 & Museum Etnobotani & 8.345 \\
5 & Prasasti Batutulis & 1.294 \\
6 & Danau Situgede & 1.631 \\
7 & Taman Ade Irma Suryani & 156.394 \\
8 & Museum Tanah & 698 \\
9 & Museum PETA & 10.399 \\
10 & Museum Perjuangan & 1.315 \\
\hline
\end{tabular}

Sumber: Dinas Pariwisata Kota Bogor

Berdasarkan Tabel 1, dapat disimpulkan bahwa setiap tahunnya Kota Bogor dikunjungi oleh jutaan wisatawan yang datang dari berbagai daerah dan kalangan. Hal ini dapat dilihat dari jumlah pengunjung pada tempat wisata milik pemerintah Kota Bogor sejumlah 1.627.763 pengunjung, di luar wisatawan yang mengunjungi tempat wisata milik swasta. Pada dasarnya sektor bidang jasa, dewasa ini sangat mendominasi di berbagai bangsa.Hal ini dapat dilihat dari banyaknya pelaku bisnis yang ikut mengambil andil serta terbuka lebarnya peluang pekerjaan yang ditawarkan dalam bidang ini.Salah satu contoh usaha di bidang jasa yang dibutuhkan oleh konsumen adalah hotel. Keberadaan hotel di tengah masyarakat dirasakan semakin penting bagi para konsumen yang membutuhkan tempat untuk menginap dalam berbagai keperluan. Konsumen yang menggunakan jasa pelayanan hotel biasanya terdiri dari para wisatawan/turis maupun para pekerja yang melakukan bisnis di daerah lain. Dengan banyaknya jumlah wisatawan serta para pekerja yang melakukan bisnis di Kota Bogor, maka industri jasa hotel melihat peluang yang sangat besar untuk menanamkan modal di Kota yang dipimpin oleh Bapak Bima Arya ini. Adapun jumlah tingkat hunian hotel di Kota Bogor disajikan pada Tabel 2.

Tabel 2. Jumlah Tingkat Hunian Hotel di Kota Bogor Tahun 2014

\begin{tabular}{llrrr}
\hline No & \multicolumn{1}{c}{ Nama Hotel } & $\begin{array}{c}\text { Jumlah Kamar } \\
\text { Tersedia }\end{array}$ & $\begin{array}{c}\text { Jumlah Kamar } \\
\text { Terjual }\end{array}$ & $\begin{array}{c}\text { Tingkat } \\
\text { Hunian }(\%)\end{array}$ \\
\hline 1 & Aston Bogor Hotel & 78.840 & 75.844 & 96,19 \\
2 & Hotel Santika & 67.525 & 64.732 & 95,86 \\
3 & Hotel Salak & 55.845 & 52.301 & 93,65 \\
4 & Sahira Butik Hotel & 43.183 & 40.313 & 93,35 \\
5 & New Mirah & 30.428 & 20.879 & 68,61 \\
6 & Papyrus Tropical Hotel & 18.878 & 10.799 & 57,20 \\
7 & Braja Mustika Hotel & 12.116 & 6.761 & 55,80 \\
8 & Hotel Pangrango 2 & 30.230 & 16.508 & 54,60 \\
9 & Hotel Sempur Park & 8.544 & 4.005 & 46,87 \\
10 & Hotel Pangrango 1 & 4.553 & 1.966 & 43,18 \\
\hline
\end{tabular}

Sumber: Dinas Pariwisata Kota Bogor 
Berdasarkan Tabel 2, dapat diketahui bahwa, total tingkat hunian Braja Mustika Hotel \& Convention Centre, Bogor pada tahun 2014 sebesar 55,80\%. Persen tingkat hunian Braja Mustika Hotel \& Convention Centre, Bogor masih dibawah nilai tingkat hunian Aston Bogor Hotel, Hotel Santika, Hotel Salak, Sahira Butik Hotel, New Mirah, dan Papyrus Tropical Hotel. Akan tetapi, persen tingkat hunian Braja Mustika Hotel \& Convention Centre, Bogor masih di atas nilai persen tingkat hunian Hotel Pangrango 2, Hotel Sempur Park dan Hotel Pangrango 1. Dalam situasi persaingan yang cukup tinggi pada industri perhotelan, maka sangat penting bagi perusahaan untuk lebih kreatif, inovatif, serta memiliki mutu pelayanan yang lebih untuk mendapatkan hati para konsumen maupun calon konsumennya. Fasilitas yang baik, keramahan para karyawan, lokasi yang strategis dan harga yang bersahabat juga menjadi salah satu pembanding yang cukup berperan bagi para konsumen untuk menentukan pilihan hotel yang akan ditujunya. Oleh sebab itu, dibutuhkan analisis yang lebih mendalam untuk mengetahui kelebihan dan kekurangan dari kualitas layanan jasa yang telah diberikan oleh Braja Mustika Hotel \& Convention Centre, Bogor hingga saat ini agar di kemudian hari Braja Mustika Hotel \& Convention Centre, Bogor dapat memperbaiki kinerja perusahaan untuk menjadi lebih baik dari sebelumnya sehingga memiliki tingkat hunian yang lebih tinggi.

\section{KAJIAN TEORI}

Pemasaran. Pemasaran merupakan salah satu kegiatan dalamperekonomian yang bukan semata-mata hanya untuk menjual barang atau jasa, akan tetapi lebih mengarah pada perpindahan suatu barang atau jasa dariprodusen ke konsumen dengan efisien dan efektif. Menurut Kotler (2008) pengertian pemasaran adalah suatu proses sosial dan manajerialdimana individu dan kelompok mendapatkan apa yang mereka butuhkan daninginkan dengan menciptakan dan mempertukarkan produk dan nilai dengan yanglain. Jadi untuk mendapatkan apa yang dibutuhkan dan diinginkan, setiap individudan kelompok melakukan proses sosial atau interaksi dengan menciptakan dan mempertukarkan produk dan nilai dengan individu serta kelompok lainnya.Definisi pemasaran yang lebih menekankan pada proses manajerial yaituproses perencanaan, penetapan harga, promosi dan distribusi, barang atau jasauntuk menciptakan pertukaran yang memuaskan tujuan seluruh individu danorganisasi. Dalam hal ini pemasaran melibatkan sejumlah fungsi manajerial yangsaling berhubungan dalam suatu proses manajemen, yaitu planning, organizing,actuating, dan controlling (Kotler, 2008).

Jasa. Jasa merupakan semua aktivitas ekonomi yang hasilnya bukan berbentukproduk fisik atau konstruksi, yang umumnya dihasilkan dan dikonsumsi secarabersamaan serta memberikan nilai tambah (misalnya kenyamanan, hiburan,kesenangan, atau kesehatan) konsumen. Tidak jauh berbeda dengan definisi tersebut, Kotler (2008) mendefinisikan jasa adalah setiap tindakan atau wujud dan tindak mengakibatkan kepemilikan apapun. Menurut Hamdani (2009), produksi jasa bisa berkaitan dengan produk fisik atau sebaliknya.

Dimensi Kualitas Jasa. Kualitas adalah keseluruhan ciri serta sifat dari suatu produk atau pelayanan yang berpengaruh pada kemampuan untuk memuaskan kebutuhan yang dinyatakan atau yang tersirat. Definisi tersebut mencerminkan kualitas yangberpusat pada konsumen. Seorang penjual atau sebuah perusahaan dapat disebutsebagai perusahaan 
berkualitas jika hampir selalu memuaskan kebanyakan kebutuhan konsumennya, dimana pelayanan yang diberikan memenuhi ataumelebihi kepentingan konsumen (Kotler, 2008).

Parasuraman, et al. 1985, mengemukakan bahwa perusahaan yang bergerak di bidang jasa sangat tergantung pada kualitas jasa yang diberikan oleh perusahaan. Mereka berpendapat bahwajasa terdiri dari lima dimensi diantaranya yaitu berwujud (tangibles), kehandalan (reliability), ketanggapan (responsiveness), jaminan dan keyakinan (assurance), dan empati (emphaty).

1. Berwujud (tangibles). Penampilan dan kemampuan sarana dan prasarana fisikperusahaan yang dapat diandalkan keadaan lingkungan sekitarnya merupakanbukti nyata dari pelayanan yang diberikan oleh pemberi jasa. Hal ini meliputifasilitas fisik (contoh: gedung, tempat parkir, interior dan lain-lain), perlengkapan danperalatan yang digunakan (teknologi), serta penampilan karyawannya.

2. Keandalan (reliability). Kepuasan harus sesuai dengan kepentingan setiapkonsumen yang berarti ketepatan waktu, pelayanan yang sama untuk seluruh konsumen tanpa kesalahan, sikap dan perilaku yang simpatik, dan denganakurasi yang tinggi.

3. Ketanggapan (responsiveness). Suatu kebijakan untuk membantu dan memberikan pelayanan yang cepat dan tepat kepada setiap konsumen, dengan penyampaian informasi yang jelas. Membiarkan konsumen menunggu persepsi yang negatif dalam kualitas pelayanan.

4. Jaminan dan kepastian (assurance). Pengetahuan, kesopansantunan, kemampuan pegawai untuk menumbuhkan rasa percaya para konsumen kepada perusahaan. Hal ini meliputi beberapa komponen antara lain komunikasi (communication), kredibilitas (credibility), keamanan (security), kompetensi (competence), dan sopan santun (courtesy).

5. Empati (emphaty). Dimana suatu perusahaan diharapkan memiliki pengertian dan pengetahuan tentang konsumen, memahami kebutuhan konsumen secaraspesifik, serta memiliki waktu pengoperasian yang nyaman bagi konsumen.

Kepuasan Konsumen. Konsumen harus dipuaskan. Jika tidak dipuaskan, mereka akan meninggalkan perusahaan dan menjadi konsumen dari pihak pesaing. Semakin banyak konsumen yang meninggalkan perusahaan, maka laba perusahaan akan menurun, karena laba berasal dari hasil penjualan.

Menurut Kotler (2008) kepuasan konsumen adalah tingkat perasaan seseorang setelah membandingkan kepuasan atau hasil yang ia rasakan dibandingkan dengan kepentingan. Konsumen yang merasa puas adalah konsumen yang menerima nilai tambah yang lebih dari perusahaan. Kepuasan konsumen merupakan suatu hal yang sangat berharga demi mempertahankan keberadaan konsumen tersebut untuk tetap berjalannya bisnis atau usaha.

Kepuasan konsumen merupakan fungsi dari kualitas pelayanan dikurangi kepentingan konsumen (Parasuraman, et al. 1985: 41 - 50) dengan kata lain dirumuskan:

1. Service Quality < Expectation. Bila ini terjadi, dapat dikatakan bahwa pelayanan yang diberikan perusahaan buruk.Selain tidak memuaskan juga tidak sesuai dengan kepentingan konsumen.

2. Service Quality = Expectation . Bila ini terjadi, dapat dikatakan bahwa pelayanan yang diberikan tidak ada keistimewaannya dan memang sudah seharusnya seperti itu. 
3. Service Quality > Expectation. Bila ini terjadi dapat dikatakan bahwa konsumen merasakan pelayanan yang diberikan oleh perusahaan tidak hanya sesuai dengan kebutuhan, namun sekaligus memuaskan dan menyenangkan.

Kerangka Pemikiran Penelitian. Dengan meningkatnya jumlah industri jasa hotel di Kota Bogor, mengakibatkan adanya persaingan antar industri jasa hotel pun tak terelakkan. Setiap industri jasa hotel harus memiliki visi \& misi yang kuat untuk dapat terus bertahan di kancah industri ini. Berdasarkan visi \& misi yang ada dibutuhkan adanya pengukuran kualitas jasa yang diukur melalui dimensi kualitas jasa dan terdiri dari kehandalan, ketanggapan, keyakinan, empati, dan berwujud. Menggunakan Metode IPAdan Metode CSI, penulis ingin mengetahui tingkat harapan dan kinerja/kepuasan konsumen terhadap layanan yang ada di Braja Mustika Hotel \& Convention Centre, Bogor. Sehingga, hasil dari penelitian tersebut pun diharapkan dapat berguna bagi pihak hotel sebagai rekomendasi alternatif agar mencapai titik maksimal dalam pelayanan yang dilakukannya. Hal ini tersebut nantinya akan menambahkan visi dan misi perusahaan agar menjadi industri Hotel yang terbaik di Kota Bogor. Kerangka pemikiran pada penelitian ini ditunjukkan pada Gambar 1.

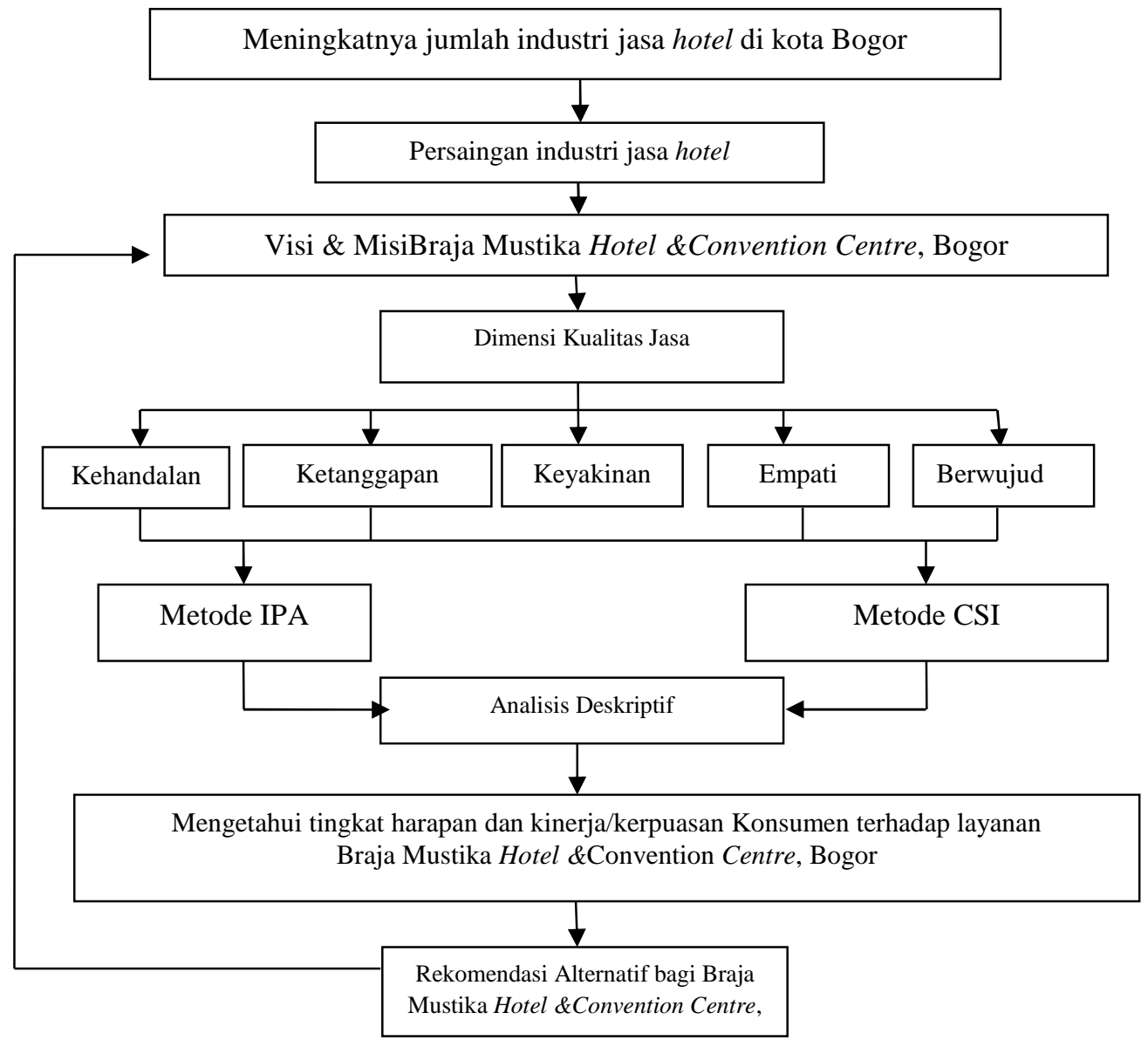

Gambar 1. Kerangka Pemikiran Penelitian 


\section{METODE}

Jenis dan Sumber Data Penelitian. Data yang digunakan dalam penelitian ini adalah data primer dan sekunder. Menurut Supranto (2011) data primer adalah data yang diperoleh atau dikumpulkan langsung di lapangan oleh orang yang melakukan penelitian, seperti data hasil wawancara, data observasi, dan sebagainya.Data sekunder merupakan data yang diperoleh atau dikumpulkan dari sumber-sumber yang telah ada, seperti buku, internet, serta laporan-laporan penelitian terdahulu.

Dalam penelitian ini, data primer diperoleh dari pengamatan langsung di lapangan, wawancara serta kuisioner. Data sekunder yang digunakan diperoleh dari studi literatur berupa jurnal penelitian, skripsi, informasi internet dan buku yang terkait dengan penelitian. Dalam penyusunan penelitian ini, penulis menggunakan unit analisis individu yaitu konsumen dari Braja Mustika Hotel \& Convention Centre, Bogor. Dalam hal ini yang menjadi unit analisis penulis adalah konsumen yang menggunakan jasa di Braja Mustika Hotel \& Convention Centre, Bogor.

Metode Penarikan Sampel. Sampel penelitian ini adalah sekelompok orang yang menghadiri meeting serta para tamu perorangan maupun kelompok yang menggunakan jasa hotel di Braja Mustika Hotel \& Convention Centre, Bogor.Sampel diambil menggunakan non-probability sampling yakni teknik purposive sampling.

Pertimbangan menggunakan teknik ini adalah karena keluar masuknya tamu hotel dan pengguna tempat meeting dan convention centre tidak tetap, sehingga sulit diketahui jumlah populasi yangsebenarnya pada waktu tertentu dan penggunaan teknik ini pun dilakukan karena penulis hanya mengambil sampel dari para tamu/konsumen yang menggunakan jasa hotel pada bulan April sampai dengan Mei 2015. Dalam hal ini, kriteria contoh yang diambil adalah konsumen Braja Mustika Hotel \& Convention Centre, Bogor baik yang baru pertama kali menginap dan menggunakan jasa convention centre atau yang telah menginap dan menggunakan jasa convention centre lebih dari satu kali. Tamu hotel yang menginap dan pengguna convention centre dianggap telah mewakili faktor dimensi kualitas pelayanan yang akan diteliti. Banyaknya contoh yang diambil adalah 100 orang.

Penentuan jumlah sampel dilakukan berdasarkan rumus Slovin, tingkat kritis sebesar 10 persen untuk mengurangi kesalahan yangdapat ditolerir, yaitu: (Usman, 2007)

$n=\frac{\mathbf{N}}{\mathbf{1}+\mathbf{N}(\mathbf{k})^{2}}$

Keterangan: $\mathrm{n}=$ Jumlah sampel

$\mathrm{N}=$ Jumlah populasi

$\mathrm{k}=$ Nilai kritis yang digunakan, yaitu 10 persen

$n=\frac{4.733}{1+4.733(0,1)^{2}}$

$=97,93($ dibulatkan menjadi 100)

Berdasarkan data yang didapat dari pihak manajemen Braja Mustika Hotel \& Convention Centre, Bogor, total pengunjung hotel dan pengguna Convention Centresejumlah 6.761 orang terhitung tanggal 1 Januari 2014 - 31 Desember 2014. 
Dalam hal pengambilan sampel ini, hanya digunakan $70 \%$ dari total populasi yang ada yaitu 4.733 orang, hal ini dikarenakan jumlah konsumen yang baru pertama kali menggunakan jasa di Braja Mustika Hotel \& Convention Centre, Bogor datang sebanyak $70 \%$.

Metode Pengolahan dan Analisis Data. Pengolahan data dilakukan dengan menggunakan kalkulator dan komputer program Microsoft Excel serta SPSS (Statistical Program for Social Science). Sebelum melakukan perhitungan IPA (Importance Performance Analysis)dan CSI (Customer Satisfaction Index), maka kuesioner yang akan digunakan harusterlebih dahulu diuji validitas dan reliabilitasnya.

Uji Validitas dan Uji Realibilitas. Ada dua syarat penting yang berlaku pada sebuah kuisioner, yaitu keharusan sebuah angket untuk validitas dan realibilitas.

Dalam pengujian validitas dari kuisioner menurut Singarimbun (2002; 137) dilakukan perhitungan korelasi antara masing - masing pernyataan dengan skor total dengan menggunakan rumus:

$$
r_{x y}=\frac{\mathbf{N} \sum \mathbf{x y}-\left(\sum \mathbf{x}\right)(\Sigma \mathbf{y})}{\left\{\left(\mathbf{N} \Sigma \mathbf{x}^{2}\right) \mathrm{r}\left(\sum \mathbf{x}\right)^{2}\right\}\left\{\left(\mathbf{N} \sum \mathbf{y}^{2}\right) \mathrm{I}(\Sigma \mathbf{y})^{2}\right\}^{\frac{1}{2}}} .
$$

Keterangan: $\quad \mathrm{N}=$ Jumlah responden

$\mathrm{X}=$ Skor masing-masing pertanyaan

$\mathrm{Y}=$ Skor Total

Menurut Usman (2007) pengujian reliabilitas dilakukan dengan menggunakan teknik belah ganjil-genap, dimana penelitian dilakukan dengan mengelompokkan skor butir bernomor ganjil sebagai belahan pertama dan kelompok skor butir genap sebagai belahan kedua.Pengujian reliabilitas dianalisis dengan menggunakan teknik Alpha Cronbach. Adapun rumusnya adalah sebagai berikut :

$$
\begin{aligned}
& \mathbf{r}=\frac{k}{k-1}\left[\mathbf{1}-\frac{\sum \delta i^{2}}{\delta^{2}}\right] \\
& \delta i^{\mathbf{z}}=\frac{\Sigma x i^{\mathbf{2}}-\left(\Sigma x i^{2}\right)}{\mathbf{N}} \ldots
\end{aligned}
$$

Keterangan: $\mathrm{r}=$ Koefisien reliabilitas yang dicari; $\mathrm{k}=$ Jumlah pertanyaan (soal); $\delta i^{\mathbf{z}}=$ Varian butir pertanyaan (soal); $\delta^{\mathbf{2}}=$ Varian skor test; $\sum \mathrm{xi}=$ Jumlah skor jawaban subjek untuk butir pertanyaan ke-n; $\mathrm{N}=$ Jumlah responden

Skala Likert. Menurut Sugiyono (2009), skala likert adalah skala yang digunakan untuk mengukur sikap, pendapat dan persepsi seseorang atau sekelompok orang tentang fenomena sosial. Data yang telah terkumpul melalui angket, kemudian penulis olah kedalam bentuk kuantitatif, yaitu dengan cara menetapkan skor jawaban dari pertanyaan yang telah dijawab oleh responden, dimana pemberian skor tersebut didasarkan pada ketentuan Sugiyono (2009). Untuk mengukur tingkat kepentingan pelayanan hotel, 
menyangkut kepuasan konsumen, digunakan Skala Likert seperti yang terdapat pada Tabel 3.

Tabel 3. Tabel Skala Likert

\begin{tabular}{cc}
\hline Skala & Keterangan \\
\hline 1 & Sangat Tidak Penting / Sangat Tidak Puas \\
2 & Tidak Penting / Tidak Puas \\
3 & Netral \\
4 & Penting / Puas \\
5 & Sangat Penting / Sangat Puas \\
\hline
\end{tabular}

Berdasarkan Tabel 3, dapat diketahui bahwa Skala Likert yang digunakan terdiri dari 5 bagian yakni Sangat Tidak Penting/Puas, Sangat Penting/Puas, Cukup Penting/Puas, Penting/Puas, dan Sangat Penting/Puas.

Importance Performance Analysis. Analisis untuk mengetahui sejauh mana tingkat kesesuaian dilihat dari tingkat harapandan kinerja/kepuasan konsumen terhadap kualitas pelayananhotel dengan menggunakan analisis tingkat kepentingan dan kepuasan atau Importance Performance Analysis sebagai berikut: (Sugiono, 2009)

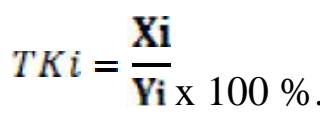

Keterangan : Tki = Tingkat kepuasan konsumen; $\mathrm{Xi}=$ Skor penilaian kinerja hotel; $\mathrm{Yi}=$ Skor penilaian harapan konsumen.

Tingkat kesesuaian adalah hasil perbandingan skor kinerja dengan skor harapan.Diagram kartesius dibuat dengan menjadi empat bagiandan dibatasi oleh dua garis yang berpotongan tegak lurus pada titik-titik $(\mathrm{X}, \mathrm{Y})$. Variabel X dan Ymasing-masing akan mengisi skor tingkat hartapan dan skor kinerja. Untuk menjabarkan atribut pada diagram kartesius digunakan rumus: (Sugiono, (2009)

$$
\begin{aligned}
& x=\frac{\sum_{i=1}^{\mathrm{n}} \mathbf{x i}}{\mathbf{n}} . \\
& y=\frac{\sum_{\mathrm{i}=1}^{\mathrm{n}} \mathbf{y i}^{\mathbf{i}}}{\mathbf{n}} .
\end{aligned}
$$

Keterangan: $\quad \mathrm{Xi}=$ Skor rata-rata tingkat kinerja; $\mathrm{Yi}=$ Skor rata-rata tingkat harapan; $\mathrm{xi}=$ Total skor tingkat kinerja; yi = Total skor tingkat harapan; $\mathrm{N}=$ Jumlah responden

Selanjutya unsur tersebut akan dibagi menjadi empat bagian ke dalam diagram kartesius yaitu diagram Prioritas Utama, diagram Pertahankan Prestasi, diagram Prioritas Rendah, dan diagram Berlebihan seperti pada Gambar 2. 
Tingkat Harapan

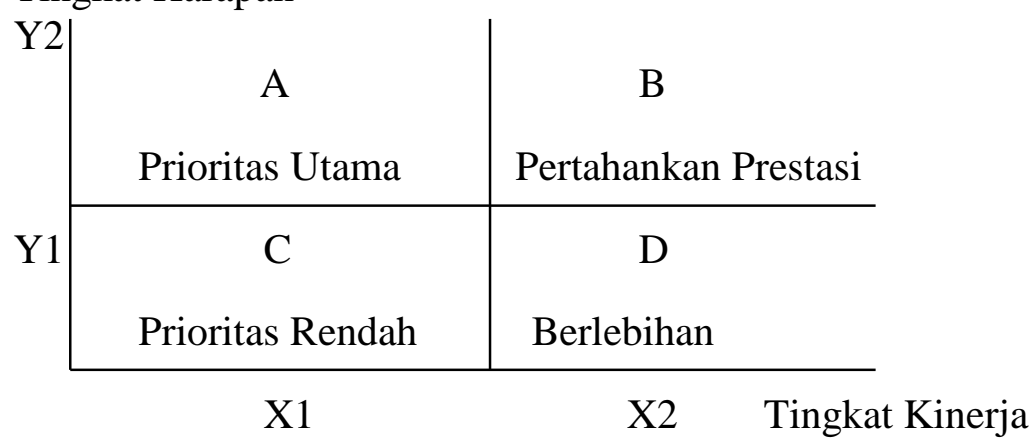

Gambar 2 . Diagram Kartesius

Dari gambar diagram kartesius di atas, dapat ditarik beberapa kesimpulan perihal keterangan isi dari diagram yang terdiri dari 4 (empat) buah kuadran tersebut, yakni: (A) Menunjukkan faktor yang dianggap mempengaruhi kepuasankonsumen, termasuk unsurunsur jasa yang dianggap sangat penting namun manajemen belum mampu melaksanakannya sesuai keinginan konsumen sehingga mengecewakan/tidak puas; (B) Menunjukkan unsur jasa pokok yang telah berhasil dilaksanakan perusahaan, untuk itu wajib dipertahankan. Dianggap sangat penting dan sangat memuaskan; (C) Menunjukkan beberapa faktor yang kurang penting pengaruhnya bagi konsumen, pelaksanaannya oleh perusahaan biasa-biasa saja; (D) Menunjukkan faktor yang mempengaruhi konsumen. Kurang penting tetapi pelaksanaannya berlebihan. Dianggap kurang penting tetapi sangatmemuaskan.

Customer Satisfaction Index. Menurut Buchori (2007), Pengukuran CSI diperlukan karena hasil daripengukuran dapat digunakan sebagai acuan untuk menentukan sasaransasaran ditahun-tahun mendatang. Tanpa adanya CSI, top management tidak dapatmenentukan tujuan dalam peningkatan kepuasan konsumen. Indeks diperlukan karena proses pengukuran kepuasan konsumen bersifat kontinyu.

Metode pengukuran CSI ini menurut Statford dalam Buchori (2007),meliputi tahaptahap berikut: (1) Menghitung Weighting Factor (WF), yaitu mengubah nilai rataan harapan menjadi angka persentase dari total rataan tingkat kinerja seluruh atributyang diuji, sehingga didapatkan total WF 100 persen; (2) Menghitung Weighting Score (WS), yaitu nilai perkalian antar nilai rataan tingkat kinerja masing-masing atribut dengan WF masing-masingatribut; (3) Menghitung Weighting Total (WT), yaitu menjumlahkan WS dari semua atribut mutu jasa; (4) Menghitung Satisfacion Index, yaitu WT dibagi skala maksimal yang digunakan (dalam penelitian ini skala maksimal adalah 5), kemudian dikali100 persen.

Tingkat kepuasan responden secara keseluruhan dapat dilihat dari kriteria tingkat kepuasan konsumen dengan lriteria sebagai berikut:

$$
\begin{aligned}
& 0,00-0,34=\text { Tidak Puas } \\
& 0,35-0,50=\text { Kurang Puas } \\
& 0,51-0,65=\text { Cukup Puas } \\
& 0,66-0,80=\text { Puas } \\
& 0,81-1,00=\text { Sangat Puas }
\end{aligned}
$$




\section{HASIL DAN PEMBAHASAN}

Penelitian ini dilakukan kepada 100 responden yang terdiri para konsumen pengguna jasa Braja Mustika Hotel \& Convention Centre, Bogor baik yang menggunakan jasa hotel maupun hanya jasa convention centre. Oleh sebab itu diperlukan adanya pengelompokkan bagi para responden yang menjadi sampel pada pengadaan penelitian ini. Gambaran Umum Profil Responden terdapat pada Tabel 4.

Tabel 4. Gambaran Umum Profil Responden

\begin{tabular}{cccc}
\hline No. & $\begin{array}{c}\text { Karakteristik } \\
\text { Responden }\end{array}$ & Pengelompokkan karakteristik & $\begin{array}{c}\text { Jumlah } \\
\text { Responden }\end{array}$ \\
\hline 1. & Usia & $<20$ tahun & 3 \\
& & $30-39$ tahun & 24 \\
& & $20-29$ tahun & 43 \\
2. & Jenis Kelamin & Laki -Laki & 30 \\
& & Perempuan & 68 \\
3. & Status & Menikah & 32 \\
& & Belum Menikah & 63 \\
4. & Pendidikan Terakhir & SLTA/SMA & 37 \\
& & Diploma & 4 \\
& & Sarjana & 11 \\
& & Pasca Sarjana & 49 \\
5. & Lainnya & 28 \\
& & Pelajar/Mahasiswa & 8 \\
& Pekerjaan & Pegawai Negeri & 3 \\
& & Wiraswasta & 17 \\
& & Pegawai Swasta & 36 \\
6. & Lainnya & 25 \\
& & Pendapatan 2.500.000,- & 19 \\
& per bulan & Rp 2.500.000,- Rp 5.000.000,- & 8 \\
& & Rp5.000.000,-- Rp 8.000.000,- & 29 \\
& & $>$ Rp 8.000.000,- & 17 \\
\hline
\end{tabular}

Sumber: Data Primer Diolah (2015)

Berdasarkan Tabel 4, karakteristik responden dibagi atas 6 kriteria, yakni: usia, jenis kelamin, status, pendidikan terakhir, pekerjaan, dan pendapatan per bulan. Dari hasil pengelompokkan karakteristik responden, ditemukan bahwa konsumen Braja Mustika Hotel \& Convention Centre, Bogor lebih banyak laki - laki yang memiliki kisaran usia 20 - 29 tahun dengan status menikah dan memiliki pendidikan terakhir sebagai Sarjana yang kemudian memiliki pekerjaan sebagai wiraswasta dengan pendapatan per bulan mencapai kisaran Rp 5.000.000,- s/d Rp 8.000.000,- setiap bulannya.

Uji Validitas dan Reliabilitas Kuisioner. Uji coba kuesioner dilakukan terhadap 30 responden dan dilanjutkan menjadi 100 responden, dimana responden merupakan konsumen yang pernah menggunakan jasa hotel maupun convention centre di Braja Mustika Hotel \& Convention Centre, Bogor. Berdasarkan perhitungan uji validitas dengan metode product moment pearson, diperoleh hasil korelasi setiap pernyataan untuk masing- 
masing atribut tingkat harapan dan tingkat kinerja. Banyaknya atribut yang diambil dalam kuesioner ini diperoleh berdasarkan hasil survey yang dilakukan sebelum kuesioner disebarkan. Seluruh nilai korelasi atau r-hasil setiap pernyataan lebih besar dari nilai $r$ tabel $(r>0,361)$ artinya semua pernyataan dianggap valid.Perhitungan Hasil Validitas dan Reliabilitas pada Setiap Atribut Kualitas Layanan terdapat pada Tabel 5.

Tabel 5. Hasil Validitas dan Reliabilitas pada Setiap Atribut Kualitas Layanan

\begin{tabular}{|c|c|c|c|c|}
\hline No & Dimensi Kualitas Layanan & $\begin{array}{c}\text { Nilai } \\
\text { Tingkat } \\
\text { Harapan }\end{array}$ & $\begin{array}{l}\text { Nilai } \\
\text { Tingkat } \\
\text { Kinerja }\end{array}$ & Keterangan \\
\hline 1 & Tampilan Gedung hotel & 0,908 & 0,553 & Valid \\
\hline 2 & $\begin{array}{l}\text { Tempat Parkir yang aman, rapi dan } \\
\text { memadai }\end{array}$ & 0,585 & 0,727 & Valid \\
\hline 3 & Interior yangterlihat rapi dan menarik & 0,672 & 0,750 & Valid \\
\hline 4 & $\begin{array}{l}\text { Fasilitas yang disediakan (Kolam Renang, } \\
\text { Wifi, Restoran, Ballroom, arena bermain } \\
\text { anak) }\end{array}$ & 0,836 & 0,699 & Valid \\
\hline 5 & $\begin{array}{l}\text { Kemampuan karyawan berkomunikasi } \\
\text { dengan baik }\end{array}$ & 0,861 & 0,719 & Valid \\
\hline 6 & $\begin{array}{l}\text { Kesigapan karyawan mengatasi keluhan } \\
\text { tamu }\end{array}$ & 0,584 & 0,699 & Valid \\
\hline 7 & $\begin{array}{l}\text { Kemudahan pemesanan kamar di hotel } \\
\text { maupun sewa tempat di convention centre }\end{array}$ & 0,831 & 0,719 & Valid \\
\hline 8 & Kemudahan cara pembayaran & 0,523 & 0,727 & Valid \\
\hline 9 & Lokasi yang strategis & 0,922 & 0,553 & Valid \\
\hline 10 & Harga/tarif hotel \& convention centre & 0,654 & 0,750 & Valid \\
\hline 11 & Image\& citra hotel & 0,609 & 0,699 & Valid \\
\hline 12 & $\begin{array}{l}\text { Ketanggapan karyawan menyelesaikan } \\
\text { keluhan dan kebutuhan tamu }\end{array}$ & 0,851 & 0,605 & Valid \\
\hline 13 & $\begin{array}{l}\text { Kepekaan karyawan terhadap keinginan } \\
\text { dan kebutuhan tamu }\end{array}$ & 0,578 & 0,699 & Valid \\
\hline 14 & Kejujuran dan profesionalisme karyawan & 0,861 & 0,699 & Valid \\
\hline 15 & Jaminan Keamanan dan kenyamanan hotel & 0,599 & 0,699 & Valid \\
\hline 16 & Pelayanan yang ramah dan sopan & 0,792 & 0,553 & Valid \\
\hline & RELIABILITAS & 0,764 & 0,758 & Reliabel \\
\hline
\end{tabular}

Sumber: Data primer diolah (2015)

Berdasarkan Tabel 5 diatas, ingin menjelaskan bahwa pengukuran yang memiliki reliabilitas tinggi, yaitu yang mampu memberikan hasil ukur yang terpercaya.Reliabilitas merupakan salah satu ciri atau karakter utama instrumen pengukuran yang baik. Hasil Uji reliabilitas terhadap 100 kuesioner menunjukkan nilai alpha ( $\alpha$ cronbach) yang lebih besar dari 0,6 dan mendekati satu, sehingga kuesioner dinyatakan reliabel. Hasil uji reliabilitas pada tingkat harapan memiliki nilai yaitu sebesar $0,764>0,60$, sedangkan hasil uji reliabilitas untuk tingkat kinerja memiliki nilai yaitu sebesar 0,758>0,60.

Importance Performance Analysis (IPA). Tingkat kesesuaian merupakan suatu analisis untuk mengetahui sejauh mana kesesuaian dilihat dari tingkat kepuasan konsumen terhadap kualitas pelayanan hotel dengan menggunakan analisis tingkat harapan dan kinerja atau Importance Performance Analysis. Hasil dari tingkat kesesuaian antara 
tingkat harapan dan tingkat kinerja terhadap setiap atribut kualitas pelayanan dijelaskan pada Tabel 6.

Tabel 6. Hasil Tingkat Kesesuaian antara tingkat harapan dan tingkat kinerja terhadap setiap atribut kualitas layanan

\begin{tabular}{|c|c|c|c|c|}
\hline No & Atribut Kualitas Layanan & $\begin{array}{l}\text { Total Skor } \\
\text { Harapan }\end{array}$ & $\begin{array}{l}\text { Total Skor } \\
\text { Kinerja }\end{array}$ & $\begin{array}{c}\text { Tingkat } \\
\text { Kesesuaian }(\%)\end{array}$ \\
\hline 1. & Tampilan Gedung hotel & 414 & 352 & 85,02 \\
\hline & $\begin{array}{l}\text { Tempat Parkir yang aman, rapi dan } \\
\text { memadai }\end{array}$ & 448 & 303 & 67,63 \\
\hline 3. & $\begin{array}{l}\text { Interior yangterlihat rapi dan } \\
\text { menarik }\end{array}$ & 460 & 308 & 66,96 \\
\hline & $\begin{array}{l}\text { Fasilitas yang disediakan (Kolam } \\
\text { Renang, Wifi, Restoran, Ballroom, } \\
\text { arena bermain anak) }\end{array}$ & 420 & 481 & 114,52 \\
\hline & $\begin{array}{l}\text { Kemampuan karyawan } \\
\text { berkomunikasi dengan baik }\end{array}$ & 477 & 434 & 90,99 \\
\hline & $\begin{array}{l}\text { Kesigapan karyawan mengatasi } \\
\text { keluhan tamu }\end{array}$ & 423 & 481 & 113,71 \\
\hline & $\begin{array}{l}\text { Kemudahan pemesanan kamar di } \\
\text { hotel maupun sewa tempat di } \\
\text { convention centre }\end{array}$ & 419 & 434 & 103,58 \\
\hline & Kemudahan cara pembayaran & 453 & 303 & 66,89 \\
\hline & Lokasi yang strategis & 410 & 352 & 85,85 \\
\hline & Harga/tarif hotel \& convention centre & 459 & 308 & 67,10 \\
\hline 11. & Image\& citra hotel & 437 & 481 & 110,07 \\
\hline 12. & 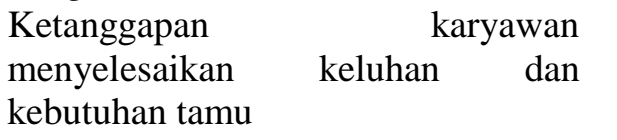 & 478 & 445 & 93,10 \\
\hline & $\begin{array}{l}\text { Kepekaan karyawan terhadap } \\
\text { keinginan dan kebutuhan tamu }\end{array}$ & 465 & 481 & 103,44 \\
\hline & $\begin{array}{l}\text { Kejujuran dan profesionalisme } \\
\text { karyawan }\end{array}$ & 477 & 481 & 100,84 \\
\hline & $\begin{array}{l}\text { Jaminan } \quad \text { Keamanan } \\
\text { kenyamanan hotel }\end{array}$ & 436 & 481 & 110,32 \\
\hline 16. & Pelayanan yang ramah dan sopan & 466 & 352 & 75,54 \\
\hline
\end{tabular}

Sumber: Data primer diolah (2015)

Berdasarkan Tabel 6, dapat dilihat bahwa tingkat kesesuaian tertinggi dimiliki oleh atribut 4 dimana para konsumen merasa sangat puas pada fasilitas yang disediakan oleh Braja Mustika Hotel \& Convention Centre, Bogor. Tingkat kesesuaian antara tingkat harapan dan tingkat kinerja dapat digunakan untuk melihat secara berurut peringkat atau rangking dari setiap atribut kualitas pelayanan yang diteliti mulai dari yang terendah sampai yang tertinggi, sehingga terlihat urutan prioritas untuk upaya peningkatan atau perbaikan kualitas mutu pelayanan pada Braja Mustika Hotel \&Convention Centre, Bogor.

Diagram kartesius merupakan suatu bentuk diagram yang terbagi menjadi empat kuadran yang dibatasi oleh dua garis yang saling berpotongan tegak lurus pada titik (X,Y), dimana sumbu $X$ (sumbu mendatar) akan mengisi skor untuk tingkat kinerja, sedangkan sumbu Y (sumbu tegak) akan mengisi skor untuk tingkat harapan. Nilai rataan merupakan hasil perhitungan nilai skor dibagi dengan jumlah responden yang berjumlah 100 orang. 
Hasil perhitungan nilai rata-rata tingkat harapan dan tingkat kinerja untuk atribut kualitas pelayanan konsumen dapat dilihat pada Tabel 7.

Tabel 7. Nilai Rataan Penilaian Tingkat Harapan dan Tingkat Kinerja pada Atribut Kualitas Pelayanan

\begin{tabular}{|c|c|c|}
\hline Atribut Kualitas Pelayanan & $\begin{array}{l}\text { Nilai Rataan Tingkat } \\
\text { Harapan (Y) }\end{array}$ & $\begin{array}{c}\text { Nilai Rataan } \\
\text { Tingkat Kinerja }(\mathrm{X})\end{array}$ \\
\hline 1. Tampilan Gedung hotel & 4,14 & 3,52 \\
\hline 2. Tempat Parkir yang aman, rapi dan memadai & 4,48 & 3,03 \\
\hline 3. Interior yangterlihat rapi dan menarik & 4,60 & 3,08 \\
\hline $\begin{array}{l}\text { 4. Fasilitas yang disediakan (Kolam Renang, Wifi, } \\
\text { Restoran, Ballroom, arena bermain anak) }\end{array}$ & 4,20 & 4,81 \\
\hline $\begin{array}{l}\text { 5. Kemampuan karyawan berkomunikasi dengan } \\
\text { baik }\end{array}$ & 4,77 & $4,, 34$ \\
\hline 6. Kesigapan karyawan mengatasi keluhan tamu & 4,23 & $4,, 81$ \\
\hline $\begin{array}{l}\text { 7. Kemudahan pemesanan kamar di hotel maupun } \\
\text { sewa tempat di convention centre }\end{array}$ & 4,19 & 4,34 \\
\hline 8. Kemudahan cara pembayaran & 4,53 & 3,03 \\
\hline 9. Lokasi yang strategis & 4,10 & 3,52 \\
\hline 10. Harga/tarif hotel \& convention centre & 4,59 & 3,08 \\
\hline 11. Image\& citra hotel & 4,37 & 4,81 \\
\hline $\begin{array}{l}\text { 12. Ketanggapan karyawan menyelesaikan keluhan } \\
\text { dan kebutuhan tamu }\end{array}$ & 4,78 & 4,45 \\
\hline $\begin{array}{l}\text { 13. Kepekaan karyawan terhadap keinginan dan } \\
\text { kebutuhan tamu }\end{array}$ & 4,65 & 4,81 \\
\hline 14. Kejujuran dan profesionalisme karyawan & 4,77 & 4,81 \\
\hline 15. Jaminan Keamanan dan kenyamanan hotel & 4,36 & 4,81 \\
\hline 16. Pelayanan yang ramah dan sopan & 4,66 & 3,52 \\
\hline RATA - RATA NILAI RATAAN & 4,46 & 4,05 \\
\hline
\end{tabular}

Sumber: Data primer diolah (2015)

Berdasarkan Tabel 7, dijelaskan bahwa nilai rataan tingkat harapan adalah 4,46 dan nilai rataan dari tingkat kinerja berada pada nilai 4,05. Nilai rataan ini sangat penting untuk menghitung nilai kepuasan konsumen yang nantinya terdapat pada perhitungan Customer Satisfaction Index.

Diagram kartesius digunakan untuk melihat kedudukan dari 16 atribut kualitas pelayanan yang diperoleh berdasarkan skor tingkat harapan dan skor tingkat kinerja dari banyaknya jumlah konsumen Braja Mustika Hotel \& Convention Centre, Bogor yang diambil untuk dilakukan penelitian dalam menghitung hasil keseluruhan dari setiap analisis yang akan digunakan. Hasil dari Diagram Kartesius terdiri dari 4 buah kuadran yaitu Kuadran A (Prioritas Utama), Kuadran B (Pertahankan prestasi), Kuadran C (Prioritas Rendah), Kuadran D (Berlebihan) yang terdapat pada Gambar 3. 


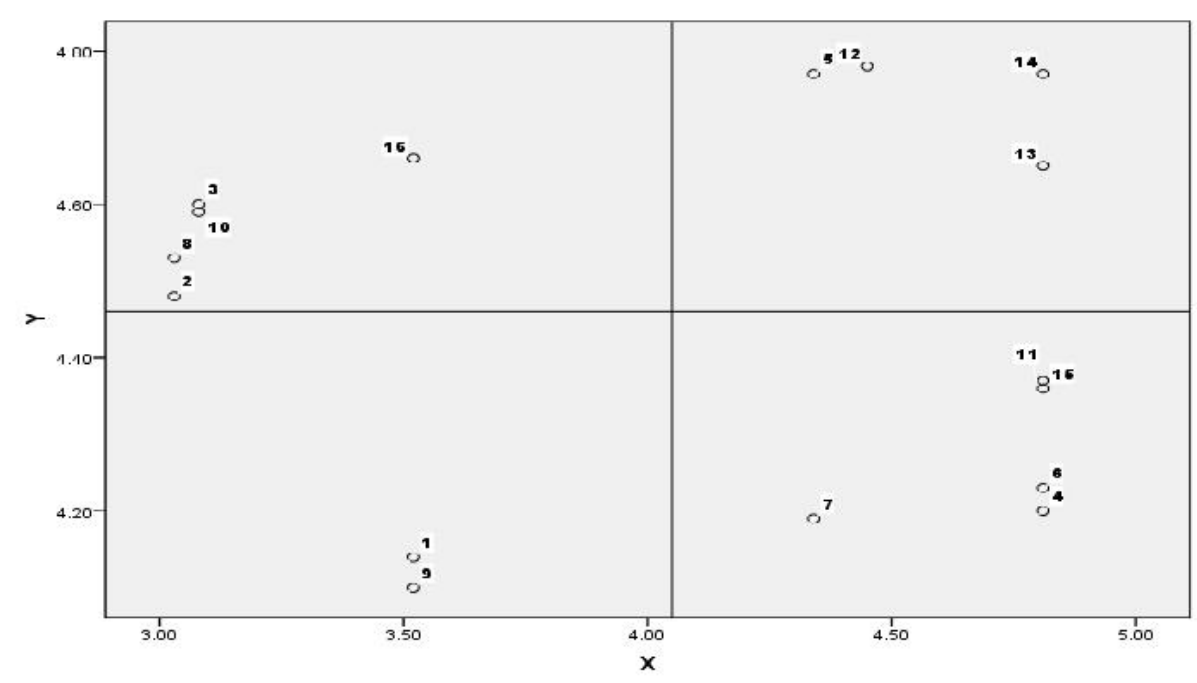

Gambar 3 Hasil Diagram Kartesius

Keterangan: 1 = Tampilan Gedung Hotel; 2 = Tempat Parkir yang aman, rapi dan memadai; 3 = Interior Hotel \& Convention Centre terlihat rapi dan menarik; $4=$ Fasilitas yang disediakan (Kolam Renang, Wifi, Restoran, Ballroom,dll); $5=$ Kemampuan karyawan berkomunikasi dengan baik; $6=$ Kesigapan karyawan mengatasi keluhan tamu; $7=$ Kemudahan pemesanan kamar di hotel maupun sewa tempat di convention centre; $8=$ Kemudahan cara pembayaran; $9=$ Lokasi yang strategis; $10=$ Harga $/$ tarif hotel \& convention centre $; 11=$ Image hotel \& convention centre $; 12=$ Ketanggapan karyawan menyelesaikan keluhan dan kebutuhan tamu; 13 = Kepekaan karyawan terhadap keinginan dan kebutuhan tamu; $14=$ Kejujuran dan profesionalisme karyawan; 15 = Jaminan Keamanan dan kenyamanan hotel dan convention centre; $16=$ Pelayanan yang ramah dan sopan

Pada Gambar 3 terlihat bahwa letak atribut-atribut kualitas pelayanan yang dianalisis tersebar menjadi empat bagian yaitu kuadran A (Prioritas Utama), kuadran B (Pertahankan Prestasi), kuadran C (Prioritas Rendah) dan kuadran D (Berlebihan). Adapun interpretasi dari diagram kartesius diatas dapat dijelaskan sebagai berikut:

1. Kuadran A (Prioritas Utama). Atribut-atribut yang berada di kuadran A menunjukkan atribut-atribut pelayanan yang penangannya perlu mendapat perhatian khusus atau diprioritaskan oleh Braja Mustika Hotel \& Convention Centre, Bogor karena keberadaan faktor-faktor ini dinilai sangat penting bagi konsumen tetapi pihak hotel belum dapat melaksanakannya sesuai dengan apa yang diharapkan oleh konsumen sehingga tingkat kepuasannya masih belum memuaskan. Atribut-atribut yang termasuk dalam kuadran ini ada 5 yaitu: (a) Tempat Parkir yang aman, rapi dan memadai (2); (b) Interior Hotel \& Convention Centre terlihat rapi dan menarik (3); (c) Kemudahan cara pembayaran (8); (d) Harga/tarif hotel \& convention centre (10); (e) Pelayanan yang ramah dan sopan (16)

2. Kuadran B (Pertahankan Prioritas). Menunjukkan atribut-atribut pelayanan Braja Mustika Hotel \& Convention Centre, Bogor yang perlu dipertahankan atau ditingkatkan karena tingkat kepuasannya pada umumnya telah sesuai dengan tingkat kepentingan atau kepentingan konsumen.Atribut yang berada pada kuadran ini jumlahnya sebanyak 4 atribut. Keempat atribut tersebut adalah: (a) Kemampuan karyawan berkomunikasi dengan baik (5); Ketanggapan karyawan menyelesaikan keluhan dan kebutuhan tamu (12); (b) 
Kepekaan karyawan terhadap keinginan dan kebutuhan tamu (13); (c) Kejujuran dan profesionalisme karyawan (14)

3. Kuadran C (Prioritas Rendah). Menunjukkan atribut-atribut yang kurang penting atau rendah pengaruhnya bagi konsumen, dan tingkat kepuasan pihak Braja Mustika Hotel \& Convention Centre, Bogor terhadap atribut - atribut ini pun tergolong rendah, sama halnya seperti kuadran A, hanya saja atribut-atribut pada kuadran A tingkat kepentingannya tinggi sehingga perlu diprioritaskan kepuasannya. Sedangkan tingkat kepentingan konsumen di kuadran $\mathrm{C}$ rendah, sehingga prioritasnya juga rendah. Sehingga walaupun kepuasannya ditingkatkan, tidak akan meningkatkan kepuasan konsumen secara signifikan. Adapun atribut yang termasuk dalam kuadran ini adalah: (a) Tampilan Gedung Hotel \& Convention Centre (1); (b) Lokasi yang strategis (9)

4. Kuadran D (Berlebihan). Pada kuadran ini, tingkat kepentingan atau kepuasan konsumen terhadap atribut-atribut pelayanan kurang atau tidak penting namun tingkat kepuasannya dinilai berlebihan. Pihak Braja Mustika Hotel \& Convention Centre, Bogor tidak perlu berkonsentrasi pada peningkatan pelayanan atribut di kuadran D ini karena kepuasannya sudah sangat baik dan dapat lebih memfokuskan pada atribut-atribut lain yang masih perlu ditingkatkan kualitas pelayanannya agar tidak kalah dengan hotel pesaing. Atribut-atribut yang termasuk dalam kuadran D atau kuadran berlebihan ini yaitu: (a) Fasilitas yang disediakan (Kolam Renang, Wifi, Restoran, Ballroom,dll) (4); (b) Kesigapan karyawan mengatasi keluhan tamu (6); (c) Kemudahan pemesanan kamar di hotel maupun sewa tempat diconvention centre (7); (d) Image \& citra hotel (11); (e) Jaminan Keamanan dan kenyamanan hotel dan convention centre (15)

Customer Satisfaction Index. Pengukuran CSI diperlukan karena hasil dari pengukuran dapat digunakan sebagai acuan untuk menentukan sasaran-sasaran di tahun-tahun mendatang. Penilaian yang dilakukan oleh konsumen Braja Mustika Hotel \& Convention Centre, Bogor, tingkat kepuasan secara keseluruhan terhadap mutu pelayanan Braja Mustika Hotel \& Convention Centre, Bogor dapat diketahui bahwa nilai CSI untuk seluruh tamu hotel adalah sebesar $80 \%$ atau 0,80. Jika didasarkan pada indeks kepuasan konsumen, maka nilai CSI ini berada pada range 0,66-0,80. Rentang nilai indeks kepuasan konsumen terdapat pada Lampiran 6. Hal ini berarti bahwa seluruh tamu hotel yang datang ke Braja Mustika Hotel \& Convention Centre, Bogor merasa puas dengan pelayanan yang diterima.Dengan melihat kondisi kondisi seperti ini, diharapkan pihak manajemen hotel terus melakukan pembaharuan dalam memberikan pelayanan dalam rangka meningkatkan lagi kepuasan konsumen dari kriteria puas menjadi sangat puas. Hasil perhitungan Customer Satisfaction Index terdapat pada Tabel 8.

Berdasarkan Tabel 8 diatas, menjelaskan bahwa total skor tingkat harapan sebesar 71,42 dan total skor tingkat kinerja sebesar 64,77. Nilai akhir total Customer Satisfaction Index sebesar 0,80 dimana hasil dari skala 0,66-0,80 merupakan hasil yang menyatakan bahwa konsumen merasa PUAS.

Implikasi Manajerial. Tingkat persaingan antar seluruh hotel yang bermunculan saat ini, menuntutpihak manajemen Braja Mustika Hotel \& Convention Centre, Bogor untuk terus meningkatkan kepuasan daripelayanannya. Implikasi manajerial dilakukan dengan melihat hasil dari analisiskualitas layananBraja Mustika Hotel \& Convention Centre, Bogor berdasarkan kepuasan konsumen yang penting untukkalangan masyarakat khususnya bagi para konsumen dari Braja Mustika Hotel \& Convention Centre, Bogor. 
Tabel 8. Hasil Perhitungan Customer Satisfaction Index (CSI)

\begin{tabular}{|c|c|c|c|c|c|}
\hline No & Atribut - Atribut & Harapan & WF & Kinerja & WS \\
\hline 1 & Tampilan Gedung hotel & 4,14 & $6 \%$ & 3,52 & 0,20 \\
\hline 2 & Tempat Parkir yang aman, rapi dan memadai & 4,48 & $6 \%$ & 3,03 & 0,19 \\
\hline 3 & Interior yangterlihat rapi dan menarik & 4,60 & $6 \%$ & 3,08 & 0,20 \\
\hline 4 & Fasilitas yang disediakan (Kolam Renang, Wifi, & & & & \\
\hline & Restoran, Ballroom, arena bermain anak) & 4,20 & $6 \%$ & 4,81 & 0,28 \\
\hline 5 & Kemampuan karyawan berkomunikasi dengan baik & 4,77 & $7 \%$ & 4,34 & 0,29 \\
\hline 6 & Kesigapan karyawan mengatasi keluhan tamu & 4,23 & $6 \%$ & 4,81 & 0,28 \\
\hline 7 & $\begin{array}{l}\text { Kemudahan pemesanan kamar di hotel maupun } \\
\text { sewa tempat di convention centre }\end{array}$ & 4,19 & $6 \%$ & 4,34 & 0,25 \\
\hline 8 & Kemudahan cara pembayaran & 4,53 & $6 \%$ & 3,03 & 0,19 \\
\hline 9 & Lokasi yang strategis & 4,10 & $6 \%$ & 3,52 & 0,20 \\
\hline 10 & Harga/tarif hotel \&convention centre & 4,59 & $6 \%$ & 3,08 & 0,20 \\
\hline 11 & Image\& citra hotel & 4,37 & $6 \%$ & 4,81 & 0,29 \\
\hline 12 & $\begin{array}{l}\text { Ketanggapan karyawan menyelesaikan keluhan } \\
\text { dan kebutuhan tamu }\end{array}$ & 4,78 & $7 \%$ & 4,45 & 0,30 \\
\hline 13 & Kepekaan karyawan terhadap keinginan dan & & & & \\
\hline & kebutuhan tamu & 4,65 & $7 \%$ & 4,81 & 0,31 \\
\hline 14 & Kejujuran dan profesionalisme karyawan & 4,77 & $7 \%$ & 4,81 & 0,32 \\
\hline 15 & Jaminan Keamanan dan kenyamanan hotel & 4,36 & $6 \%$ & 4,81 & 0,29 \\
\hline 16 & Pelayanan yang ramah dan sopan & 4,66 & $7 \%$ & 3,52 & 0,23 \\
\hline & TOTAL & 71,42 & $100 \%$ & 64,77 & 4,05 \\
\hline & TOTAL CSI $=(4,05: 5) \times 100 \%$ & \multicolumn{4}{|c|}{0,8} \\
\hline
\end{tabular}

Sumber: Data Primer diolah (2015)

Menurut W. Chan Kim dan Renee Mauborgne (2005), terdapat 4 Actions Framework yang harus suatu perusahaan miliki untuk mempertahankan kualitas serta mutu kepuasan pelayanannya. Apabila 4 Actions Framework tersebut dapat diatasi dan dilakukan dengan baik, W.Chan Kim dan Renee Mauborgne percaya bahwa akan timbul nilai kurva baru yang akan menambahkan tingkat kepuasan konsumen dan laba perusahaan. Framework tersebut terdiri dari FrameworkEliminate, Framework Raise, Framework Reduce, Framework Create.Four Actions Framework dapat dilihat pada Gambar

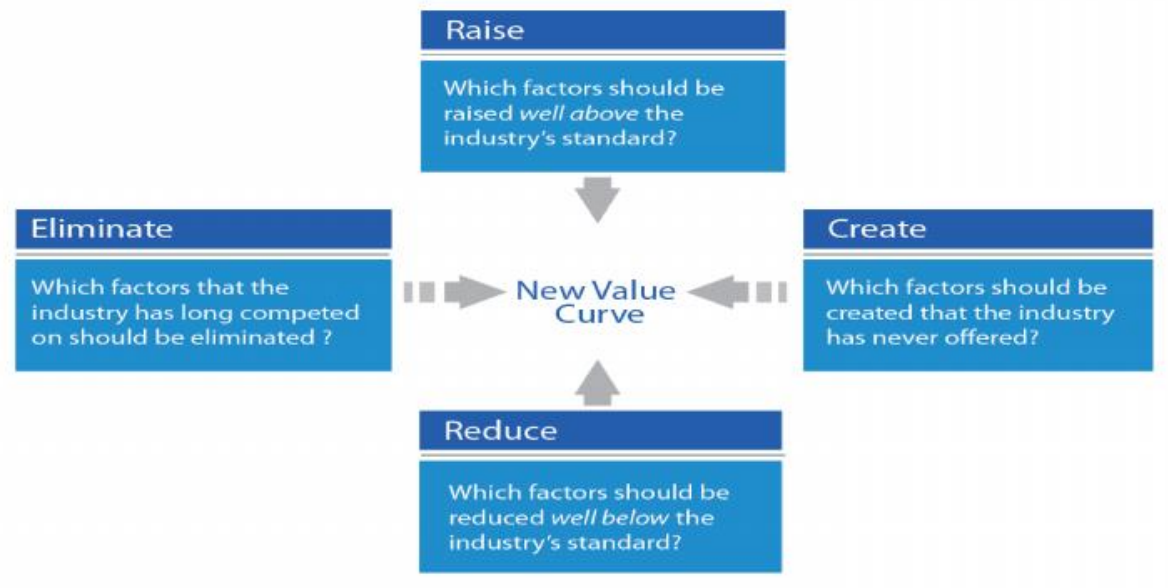

Gambar 4. Four ( 4 ) Actions Framework 
Berdasarkan Gambar 4, dapat dilihat bahwa Actions Frameworkterdiri dari 4 bagian, dimana di setiap Frameworkterdapat atribut - atribut nyata yang dapat ditingkatkan (Raise), diciptakan (Create), dihilangkan (Eliminate), maupun dikurangi (Reduce). Pengaplikasian dalam implikasi manajerial dari 4 Actions Framework (Raise, Create, Reduce dan Eliminate) terdapat pada Tabel 9.

Tabel 9. Implikasi Manajerial dari 4 Actions Framework

\begin{tabular}{|c|c|c|c|c|c|}
\hline No. & Atribut Kualitas Layanan & Raise & Create & Reduce & Eliminate \\
\hline 1 & Tampilan Gedung hotel & $\checkmark$ & - & - & - \\
\hline 2 & $\begin{array}{l}\text { Tempat Parkir yang aman, rapi dan } \\
\text { memadai }\end{array}$ & $\checkmark$ & $\checkmark$ & - & - \\
\hline 3 & Interior yangterlihat rapi dan menarik & $\checkmark$ & - & - & - \\
\hline 4 & $\begin{array}{l}\text { Fasilitas yang disediakan (Kolam } \\
\text { Renang, Wifi, Restoran, Ballroom, } \\
\text { arena bermain anak) }\end{array}$ & $\checkmark$ & - & - & - \\
\hline 5 & $\begin{array}{l}\text { Kemampuan karyawan berkomunikasi } \\
\text { dengan baik }\end{array}$ & $\checkmark$ & - & - & - \\
\hline 6 & $\begin{array}{l}\text { Kesigapan karyawan mengatasi } \\
\text { keluhan tamu }\end{array}$ & $\checkmark$ & - & - & - \\
\hline 7 & $\begin{array}{l}\text { Kemudahan pemesanan kamar di hotel } \\
\text { maupun sewa tempat di convention } \\
\text { centre }\end{array}$ & $\checkmark$ & $\checkmark$ & - & - \\
\hline 8 & Kemudahan cara pembayaran & $\checkmark$ & $\checkmark$ & - & - \\
\hline 9 & Lokasi yang strategis & - & - & - & - \\
\hline 10 & Harga/tarif hotel \& convention centre & - & - & - & - \\
\hline 11 & Image\& citra hotel & $\checkmark$ & - & - & - \\
\hline 12 & $\begin{array}{l}\text { Ketanggapan karyawan menyelesaikan } \\
\text { keluhan dan kebutuhan tamu }\end{array}$ & $\checkmark$ & - & - & - \\
\hline 13 & $\begin{array}{l}\text { Kepekaan karyawan terhadap } \\
\text { keinginan dan kebutuhan tamu }\end{array}$ & $\checkmark$ & - & - & - \\
\hline 14 & $\begin{array}{l}\text { Kejujuran dan profesionalisme } \\
\text { karyawan }\end{array}$ & $\checkmark$ & - & - & - \\
\hline 15 & $\begin{array}{l}\text { Jaminan Keamanan dan kenyamanan } \\
\text { hotel }\end{array}$ & - & $\checkmark$ & - & - \\
\hline 16 & Pelayanan yang ramah dan sopan & $\checkmark$ & - & - & - \\
\hline
\end{tabular}

Sumber: Data Primer Diolah (2015)

Berdasarkan Tabel 9, tidak semua atribut dapat dimasukkan ke dalam kategori 4 Actions Framework. Penulis berpendapat bahwa setiap Actions Framework memiliki atribut - atribut yang berbeda dan dapat diciptakan sendiri sesuai dengan kebutuhan perusahaan yang membutuhkan strategi ini untuk memperoleh hasil maupun keuntungan yang lebih besar serta kepuasan yang dirasakan oleh konsumen yang telah menggunakan jasa di Braja Mustika Hotel \& Convention Centre, Bogor. Berikut beberapa atribut kualitas layanan yang seharusnya ada di 4 Actions Framework:

1. Framework Eliminate. Merupakan suatu framework yang di dalamnya berisikan tentang atribut - atribut yang harus dihilangkan untuk meningkatkan mutu kualitas pelayanan.Pengaplikasian padaBraja Mustika Hotel \& Convention Centre, Bogor: (a) Tempat parkir yang berundak dan curam; (b) Kesulitan dalam pembayaran menggunakan kartu debit dan kredit 
2. Framework Raise. Merupakan suatu frameworkyang berisikan atribut - atribut yang harus ditingkatkan oleh pihak perusahaan untuk meningkatkan mutu kualitas pelayanan. Pengaplikasian padaBraja Mustika Hotel \& Convention Centre, Bogor: (a) Kejujuran dan profesionalisme karyawan; (b) Kepekaan karyawan terhadap keinginan dan kebutuhan tamu; (c) Ketanggapan karyawan menyelesaikan keluhan dan kebutuhan tamu; (d) Kemampuan karyawan berkomunikasi dengan baik; (e) Image/citra hotel yang baik harus terus dipertahankan dan ditingkatkan

3. Framework Reduce. Merupakan suatu framework yang berisikan atribut - atribut yang harus dikurangi demi meningkatkan mutu kualitas pelayanan. Pengaplikasian padaBraja Mustika Hotel \& Convention Centre, Bogor: (a) Harga/tarif yang disesuaikan dengan mutu dan pelayanan hotel

4. Framework Create. Merupakan suatu framework yang berisikan atribut -atribut yang harus diciptakan untuk meningkatkan mutu kualitas pelayanan agar mencapai tingkat kepuasan konsumen dan laba yang maksimum. Pengaplikasian padaBraja Mustika Hotel \& Convention Centre, Bogor: (a) Mengadakan promosi melalui iklan di media sosial dan media cetak; (b) Tempat Parkir yang aman, rapi, dan memadai; (c) Kemudahan pemesanan kamar di hotel maupun sewa tempat di convention centre.

Selain implikasi manajerial terhadap 4 Actions Framework yang terdapat pada Blue Ocean Strategy, penulis menerapkan implikasi manajerial terhadap Planning, Organizing, Actuating dan Controlling. Dilihat dari segi Perencanaan (Planning), perusahaan harus memiliki strategi yang baik dalam memasarkan produk jasanya, dalam hal ini jasa hotel. Mengadakan promosi, potongan harga (discount), pengiklanan, serta peningkatan kualitas layanan jasa dirasa sangat baik demi kelangsungan Product Life Cycle pada perusahaan.

Pengorganisasian (Organizing) dirasa sudah cukup mumpuni dalam mengatur dan mengorganisasi para karyawan dan pekerja dilihat dari berbagai job description yang jelas dan adanya struktur organisasi yang terpusat. Selain itu, perusahan pun harus lebih baik lagi dalam merealisasikan segala macam formulasi strategi yang telah dirancang (implementasi strategi).

Berdasarkan strategi yang baik, pengorganisasian yang baik serta adanya realisasi strategi yang baik, perusahaan harus dapat mengendalikan maupun mempertahankan prestasi yang ada dan menambahkan strategi yang lebih baik lagi agar dapat menjadi perusahaan nomor satu di Kota Bogor pada bidang industri jasa perhotelan.

\section{PENUTUP}

Simpulan. Berdasarkan uraian yang telah disajikan sebelumnya, maka dapat disimpulkan hal - hal sebagai berikut: (1) Pengunjung Braja Mustika Hotel \& Convention Centre, Bogor didominasi oleh laki-laki yang usianya berkisar 30 - 39 tahun dengan status menikah serta memiliki pendidikan akhir Sarjana. Pengunjung yang menginap sebagian besar bertujuan untuk berwisata dan bertujuan bisnis, karena sebagian besar pengunjungnya bekerja sebagai pegawai swasta dan wiraswasta. Pendapatan rata-rata pengunjung yang menginap di Braja Mustika Hotel \& Convention Centre, Bogor berkisar Rp 5.000.000,- s/d Rp 8.000.000,-.; (2) Tingkat harapan terhadap kualitas layanan pada Braja Mustika Hotel \& Convention Centre, Bogor berada pada skor rata - rata 4, 46 dari skala 1 - 5 sehingga dapat dikategorikan rata - rata atribut untuk pengukuran kualitas layanan sangatlah penting; (3) Tingkat kinerja konsumen pada Braja Mustika Hotel \& Convention Centre, Bogor berada pada skor rata - rata 4,05 dari skala 1 - 5 sehingga 
dapat dikategorikan rata - rata atribut untuk pengukuran kualitas layanan Puas.Nilai dari Customer Satisfaction Index (CSI)yang telah dihitung mencapai angka 0,80 dimana dari skala yang ada nilai tersebut masuk dalam tingkatan 0,66 - 0,80 dimana konsumen merasa PUAS dengan kualitas layanan yang telah diberikan oleh Braja Mustika Hotel \& Convention Centre, Bogor

\section{DAFTAR RUJUKAN}

Aryani, Rosinta, Febriana. (2010) "Pengaruh Kualitas Layanan terhadap Kepuasan Pelanggan dalam Membentuk Loyalitas Pelanggan”. Jurnal Ilmu Administrasi dan Organisasi.Vol 17 No 02.

Buchori A. (2007) Manajemen Pemasaran dan Pemasaran Jasa. Bandung (ID): Alfabeta.

Devi AB. (2011) "Pengaruh Bauran Pemasaran dalam Bisnis Restoran Terhadap Kepuasan dan Loyalitas Konsumen pada Rumah Makan Lestari Jember". Jember (ID): Fakultas Ekonomi Universitas Jember.

Hasan A. (2008) Marketing. Yogyakarta (ID): Media Pressindo.

Joko P. (2009) "Analisis Kepuasan Konsumen Ditinjau Dari Kualitas Pelayanan Hotel Grand Setiakawan di Surakarta". Surakarta (ID): Fakultas Ekonomi Universitas Sebelas Maret

Kotler P. (2008) Manajemen Pemasaran. Jakarta (ID): PT.Macanan Jaya Cemerlang. Terjemahan dari: Marketing Management.

Lupiyoadi R, Hamdani. (2009) Manajemen Pemasaran Jasa. Jakarta (ID): SalembaEmpat. Marito S. (2010) "Analisis Tingkat Kepuasan Pelanggan Terhadap Kualitas Pelayanan Mutu Hotel”. Sahira Butik Hotel.Bogor (ID): Fakultas Ekonomi Institut Pertanian Bogor.

Sawitri, Kertiyasa, Abdullah. (2013) "Pengaruh Kualitas Pelayanan Terhadap Kepuasan dan Loyalitas Pelanggan Tegal Sari Accomodation di Ubud". Jurnal Manajemen, Strategi Bisnis, dan Kewirausahaan. Vol 7 No 1.

Siti RA. (2013) "Hubungan Kompensasi dengan Kepuasan Karyawan di Braja Mustika Hotel \& Convention Centre Bogor". Bogor (ID): Fakultas Ekonomi Institut Pertanian Bogor.

Sugiyono. (2009) Statistik untuk Metode Penelitian. Bandung (ID): Alfabeta

Usman H. (2007) Pengantar Statistik. Jakarta (ID): Bumi Aksara. 